\title{
COMPARISON OF EUROPEAN UNION PUBLIC HEALTH SYSTEMS*
}

\author{
Davor Mance ${ }^{1}$ \\ Nenad Vretenar ${ }^{2}$ \\ Jelena Gojković ${ }^{3}$
}

DOI: https://doi.org/10.31410/ITEMA.S.P.2019.65

\begin{abstract}
This paper deals with public health systems of European Union Member States. We try to analyse and compare the public health budget allocation systems in existence in the EU. We analyse their differences and try to explain where the differences come from. We concentrate on the impact of differences in economic estimates in decision making on the allocation of scarce funds. We try to answer the question whether countries with lower income per capita compensate the lack of funds, lower capital endowment, and the impossibility to invest in equipment with larger labour endowment or improvement in human capital. On contraire, we find that some of the former transition countries experience a strong brain drain of medical personnel. Thus, former transition countries with relative stronger health personnel endowments tend to lose their qualified labour force to the more capital-endowed developed nations confirming the brain-drain hypothesis and refuting the hypothesis that labour is a relatively immobile production factor.
\end{abstract}

Keywords: Public Health, Health Management Systems, Health Economics, Brain Drain.

\section{INTRODUCTION}

$\mathrm{R}$ esearch questions we wished to answer were: what are the similarities and differences in health management systems in European Union Member States (EU MSs), what policies caused those differences, and are there any reasons for concern because of these differences. Our main question is concentrated around the problem of brain drain of health care personnel. Lower income, mostly Central and Eastern European Countries (CEECs) that underwent the process of political and economic transformation still unable to provide higher wages comparable to the higher income old EU MSs, risk the process of brain drain on their qualified health care personnel. We look for discrepancies in the number of newly issued qualifications for such personnel, the number of newly employed personnel and from the differences between them, we conjecture the migration of qualified health care personnel from lower income EU MSs to the higher income EU MSs. The ultimate question is that of labour mobility in the health care services sector, and the resulting brain drain of these highly trained professionals, ultimately leading to a "beggar-thy-neighbour" policies with poorer countries financing the fixed and sunk costs of personnel education and training of the richer ones.

Health, and its inverse: illness are phenomena of certain medical content with an economic and financial dimension. Healthcare is a subsystem of the whole socio-economic system, from which their conditionality and interdependence arise. Healthcare, forms an integral part of the economic system, which regulates the scope of the delivery and structure of health services. Health sys-

* This paper was financially supported by the University of Rijeka project: uniri-drustv-18-284-1456.

$1 \quad$ University of Rijeka, Faculty of Economics, Ivana Filipovića 4, Rijeka, Croatia

2 University of Rijeka, Faculty of Economics, Ivana Filipovića 4, Rijeka, Croatia

3 University of Rijeka, Faculty of Economics, Ivana Filipovića 4, Rijeka, Croatia 
tem, because of its risky nature, and spillover effects on the entire economy, is usually organised under governmental control (Arrow, 1963). „In relation to health, the economic system should ensure: (1) the optimal amount of resources allocated to health care, (2) the optimal use of these resources, (3) the optimal distribution of health care, (4) the optimal allocation of resources between current and investment spending in health " (Santerre and Neun, 2007). The goal of social health care policies is to extend life expectancy and to improve the quality of life by introducing new or improved treatments and standards of care, by promoting prevention and lower morbidity through healthier lifestyles, national screening programmes, regular and free check-ups, and improving the quality of life for chronic patients. Health economics is an interdisciplinary field of scientific research and integral part of modern management in any health care system as it deals with rational allocation of resources in healthcare. At the forefront of health economics is the creation of conditions for optimal use of a limited health care budget. EU MSs have different measures of success at allocating their scarce budgetary resources. One has to bear in mind that these differences are compared by using different benchmarks as the countries that are compared have different GDPs, living standards, demographics and consequently opportunity costs.

\section{ALTERNATIVE HEALTH SYSTEMS IN EU MEMBER STATES}

Two radically different health management systems are present in the EU: the mixed public-private system as present today in Germany and the pure single-payer centralised system as present in the UK. The pure private health management system is nowhere in existence, not even in the USA, where large governmental Medicare and Medicaid schemes are put in place.

\subsection{The mixed public-private health management system}

Germany is the country of origin of the system of socialised medical care. It is based on the foundations laid down by the original Bismarck social security system. After the Second World War, the system was modernized in the direction of subsidiarity, largely under the reminding negative experience of National Socialism and the new influence of the ordo-liberal ideas of Walter Eucken. Therefore, the health care system is relatively autonomous from the federal state but kept and improved the full coverage for health care services and sickness benefits. The German system is organised as a parallel system of on the one side a privatised insurance, hospitalisation and care, and on the other a social Statutory Insurance System organized around regional (Länder) insurances, the so-called Allgemeine Ortliche Krankenkassen (AOKs). People are allowed to opt out of the state system and into the private insurance. The public health care sector still provides the majority of health care services and produces the majority of healthcare costs. Hospitals are mostly managed by local or regional authorities. Private health expenditures include public sector co-payments. The public-private mix in the German health care system is more pronounced than in any other EU MS. The private health care sector provides for market prices that do not exist in a pure single-payer system and thus for a possibility to compare costs and outcomes of alternative health technologies. Market systems provide for common denominators and under right circumstances may entice competition with resulting cost savings and increases in effectiveness. Multi-payer systems call for much more diverse health technology assessments (HTA) comparing not only costs of different treatments for a certain outcome, but also comparing different outcomes. Multi-payer systems use the patient co-payment system to strengthen patients' decision-making role by giving them direct information on prices and "skin in the game". Multi-payer systems use health technologies in a decentralized fashion, reflecting individual preferences, as opposed to applying a population-wide decision rule of single-payer systems. (Santerre and Neun, 2007; Ottewill, 1996) 


\subsection{Pure single-payer systems of socialised medicine}

The pure single-payer system such as the United Kingdom National Health Service (NHS) and its Scandinavian counterparts, take decisions about acceptance of health technologies and reimbursements on behalf of the population. It is thus necessary to have an informationally centralized process in which available evidence is considered and a decision is made according to a given decision rule. Economic evaluations are a necessity for single-payer systems. The UK National Institute for Health and Care Excellence (NICE) assesses clinical outcomes and cost-effectiveness of a wide range of health technologies before issuing guidance for their use in the National Health Service (Drummond, 2015). Currently, NICE uses the Quality Adjusted Life Years (QALY) that simultaneously capture gains from reduced morbidity (quality gains) and reduced mortality (quantity gains), and combine these into a single commensurable measure. The trade-off between quantities and qualities must exhibit constant proportionality for the QALY to be a viable measure at least in theory. Unfortunately, this is not the case (Drummond, 2015). As in any socialist system deprived of market prices, the only way to introduce prices is to acquire them from a market system. All market prices regarding health technologies, and especially pharmaceuticals, are imputed from the US market, and other market systems.

\section{PUBLIC HEALTH SYSTEM DIFFERENCES IN EU MEMBER STATES}

The differences in opportunity costs of health are best seen by looking at total health expenditures in \% of GDP. Countries with higher GDPs also have a higher health expenditure relative to their GDP. The poorest among the countries are also among the countries with the lowest relative expenditure on health, and the countries with the highest GDP are among the ones with the highest relative health expenditures (Table 1). The difference in opportunity costs of health is due to a complex set of differences spanning from differences in system effectiveness, over the ability to pay, to the willingness to pay ultimately resulting in different social preferences with higher income countries having absolutely and relatively higher health expenditures. One needs to bear in mind that absolute differences are even greater than the relative ones once per capita incomes are taken into account. An even larger difference exists between prices of non-tradeable health services, especially those involving specialised labour. According to economic theory, a country will have a comparative advantage in producing goods that are intensive in the factor with which it is relatively abundant. Accordingly, it is expected the poorer EU MSs to compensate for the lack of capital endowment with specialised labour in health services. But human capital endowed labour in the EU is ultimately a mobile factor.

Table 1 tries to stress out the correlation between relative GDP per capita and relative health expenditure as a percentage of GDP. Wealthier countries have higher health expenditures.

Comparable countries in GDP p.c. have comparable results in health expenditures. One needs to bear in mind the even more exacerbated differences in absolute (not relative) health expenditures in richer EU MSs. As per capita incomes grow, relative health expenditures also grow due to increasing opportunity costs of health and Baumol-Bowen effects, resulting in an even larger total health expenditure. The Baumol-Bowen effect represents the rise of salaries in jobs producing untradeables experiencing low increase of labour productivity, in response to rising salaries in other jobs that experienced higher labour productivity growth. Since health services are non-tradeable and human capital intensive, they are well suited to demonstrate this effect (Table 1). If a production factor is mobile, it flows where it earns greater rewards, and consequently, capital rich countries end up with 
the required complementary human capital. To this migration contribute both push factors in form of low wages, low social status and scarce future prospects of emigration countries as well as pull factors in form of high wages, better social status and future prospects of immigration countries. The results are best seen in the number of practicing nurses per 100.000 inhabitants of EU MSs (Figure 1).

Table 1. GDP per capita in $€$ and health expenditures as \% of GDP

\begin{tabular}{|c|c|c|c|c|c|}
\hline & Country & GDP p. c. in 2011 & $\begin{array}{c}\text { Health exp. as \% of } \\
\text { GDP in } 2011\end{array}$ & GDP p. c. in 2016 & $\begin{array}{l}\text { Health exp. as \% of } \\
\text { GDP in } 2016\end{array}$ \\
\hline 1 & Austria & $€ 36.300$ & $10,0 \%$ & $€ 36.430$ & $10,4 \%$ \\
\hline 2 & Belgium & $€ 33.590$ & $10,0 \%$ & $€ 34.810$ & $10,0 \%$ \\
\hline 3 & Bulgaria & $€ 5.300$ & $7,1 \%$ & $€ 6.050$ & $8,2 \%$ \\
\hline 4 & Croatia & $€ 10.480$ & $7,8 \%$ & $€ 11.050$ & $7,2 \%$ \\
\hline 5 & Czechia & $€ 15.200$ & $7,0 \%$ & $€ 16.520$ & $7,1 \%$ \\
\hline 6 & Cyprus & $€ 22.900$ & $6,6 \%$ & $€ 22.360$ & $6,9 \%$ \\
\hline 7 & Denmark & $€ 44.240$ & $10,2 \%$ & $€ 46.720$ & $10,4 \%$ \\
\hline 8 & Estonia & $€ 12.010$ & $5,8 \%$ & $€ 13.650$ & $6,7 \%$ \\
\hline 9 & Finland & $€ 35.810$ & $8,9 \%$ & $€ 35.280$ & $9,5 \%$ \\
\hline 10 & France & $€ 31.210$ & $11,2 \%$ & $€ 31.770$ & $11,5 \%$ \\
\hline 11 & Germany & $€ 33.200$ & $10,7 \%$ & $€ 34.700$ & $11,1 \%$ \\
\hline 12 & Greece & $€ 18.500$ & $9,1 \%$ & $€ 17.110$ & $8,5 \%$ \\
\hline 13 & Hungary & $€ 10.110$ & $7,5 \%$ & $€ 11.410$ & $7,4 \%$ \\
\hline 14 & Ireland & $€ 36.760$ & $10,7 \%$ & $€ 50.710$ & $7,4 \%$ \\
\hline 15 & Italy & $€ 27.020$ & $8,8 \%$ & $€ 26.010$ & $8,9 \%$ \\
\hline 16 & Latvia & $€ 9.200$ & $5,6 \%$ & $€ 11.030$ & $6,2 \%$ \\
\hline 17 & Lithuania & $€ 9.790$ & $6,5 \%$ & $€ 12.040$ & $6,7 \%$ \\
\hline 18 & Luxembourg & $€ 79.310$ & $6,1 \%$ & $€ 82.880$ & $6,2 \%$ \\
\hline 19 & Malta & $€ 16.060$ & $8,6 \%$ & $€ 20.090$ & $9,3 \%$ \\
\hline 20 & Netherlands & $€ 38.880$ & $10,5 \%$ & $€ 39.810$ & $10,4 \%$ \\
\hline 21 & Poland & $€ 9.860$ & $6,2 \%$ & $€ 11.260$ & $6,5 \%$ \\
\hline 22 & Portugal & $€ 16.720$ & $9,5 \%$ & $€ 17.010$ & $9,1 \%$ \\
\hline 23 & Romania & $€ 6.350$ & $4,7 \%$ & $€ 7.720$ & $5,0 \%$ \\
\hline 24 & Slovakia & $€ 12.980$ & $7,4 \%$ & $€ 14.550$ & $7,1 \%$ \\
\hline 25 & Slovenia & $€ 17.870$ & $8,6 \%$ & $€ 18.540$ & $8,5 \%$ \\
\hline 26 & Spain & $€ 22.770$ & $9,1 \%$ & $€ 23.760$ & $9,0 \%$ \\
\hline 27 & Sweden & $€ 40.820$ & $10,7 \%$ & $€ 42.910$ & $10,9 \%$ \\
\hline 28 & UK & $€ 29.960$ & $8,4 \%$ & $€ 32.050$ & $9,8 \%$ \\
\hline
\end{tabular}

\section{Sources: EUROSTAT, WHO.}

The largest number of nurses per hundred thousand inhabitants is found in Denmark (over 1,600), Finland (over 1400), Germany (over 1200) and Luxembourg (about 1200) as well as Sweden (about 1100). The lowest relative number of nurses is found in Greece, Bulgaria and Cyprus. Data for France, Ireland, Portugal and Slovakia were not available.

The obvious question is the one regarding the disproportionately high number of nurses in Denmark, Finland, Germany and Luxembourg. These numbers correspond to the growing share of elderly people in these countries. Certainly, this is not the only reason as Italy, Greece, Croatia, as well as some other countries have a requirement for a higher number of nurses due to a high share of elderly people and nevertheless have only about 500 nurses per 100.000 inhabitants. Besides the requirement for nurses, a stronger determinant is the ability to pay which is higher in the former than in the latter countries. Also, this profession in terms of living and working conditions as well as the salary, has still much to wish for in the latter countries. Thus, push factors for these practitioners are as much as important as the pull factors. 


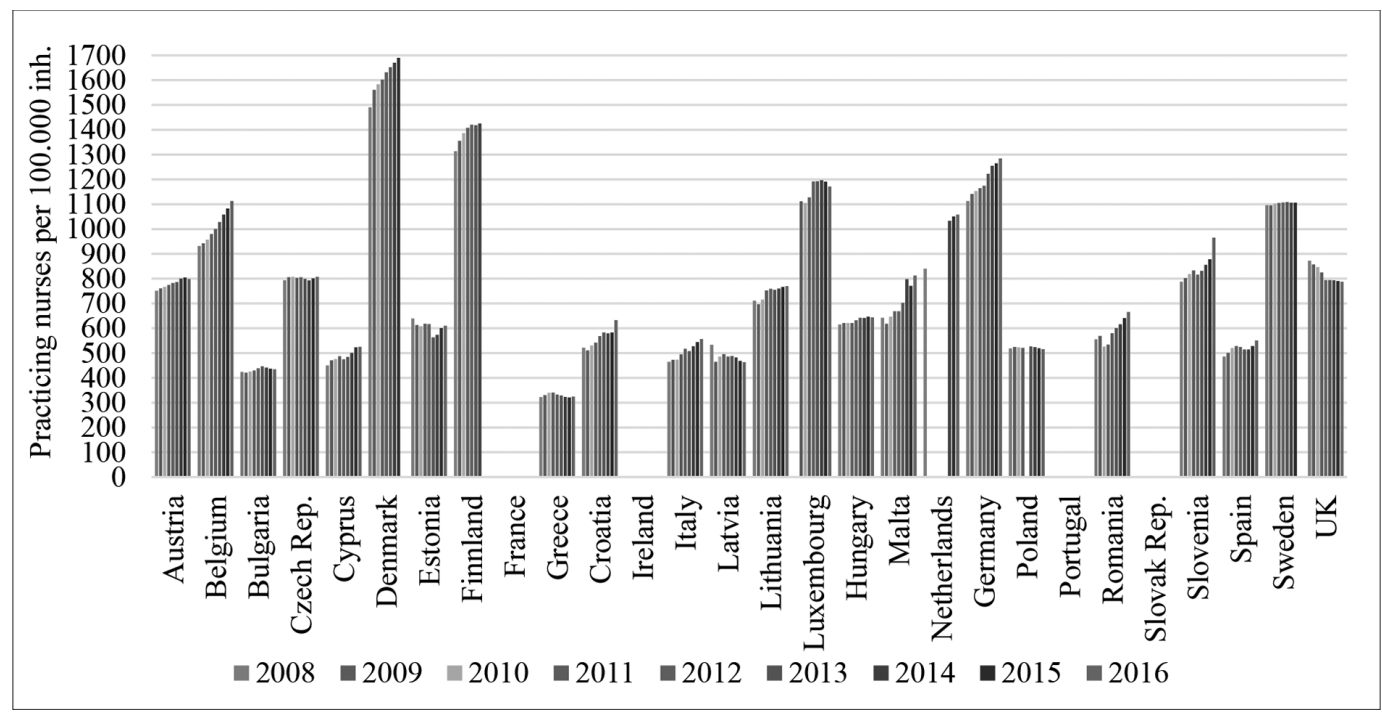

Figure 1. Number of practicing nurses per 100.000 inhabitants

Source: EUROSTAT.

There is an increasing interest from medical students, nurses and technicians to emigrate, and the obvious immigration countries are those with better working and living conditions. Greece has the lowest number of nurses, although at the same time one of the highest requirements for them. Budgetary reductions due to the Greek debt crisis contributed to poor working conditions in Greek hospitals. The Greek national health system copes with these reductions with a policy of ,open hours” for hospital visits, which is why family members stay with patients for many hours and provide informal assistance and care.

The following two charts are of special interest as they show differences between the number of graduate physicians per 100.000 inhabitants and the actual number of employed physicians per 100.000 inhabitants. From these differences we might conjecture the migration trend.

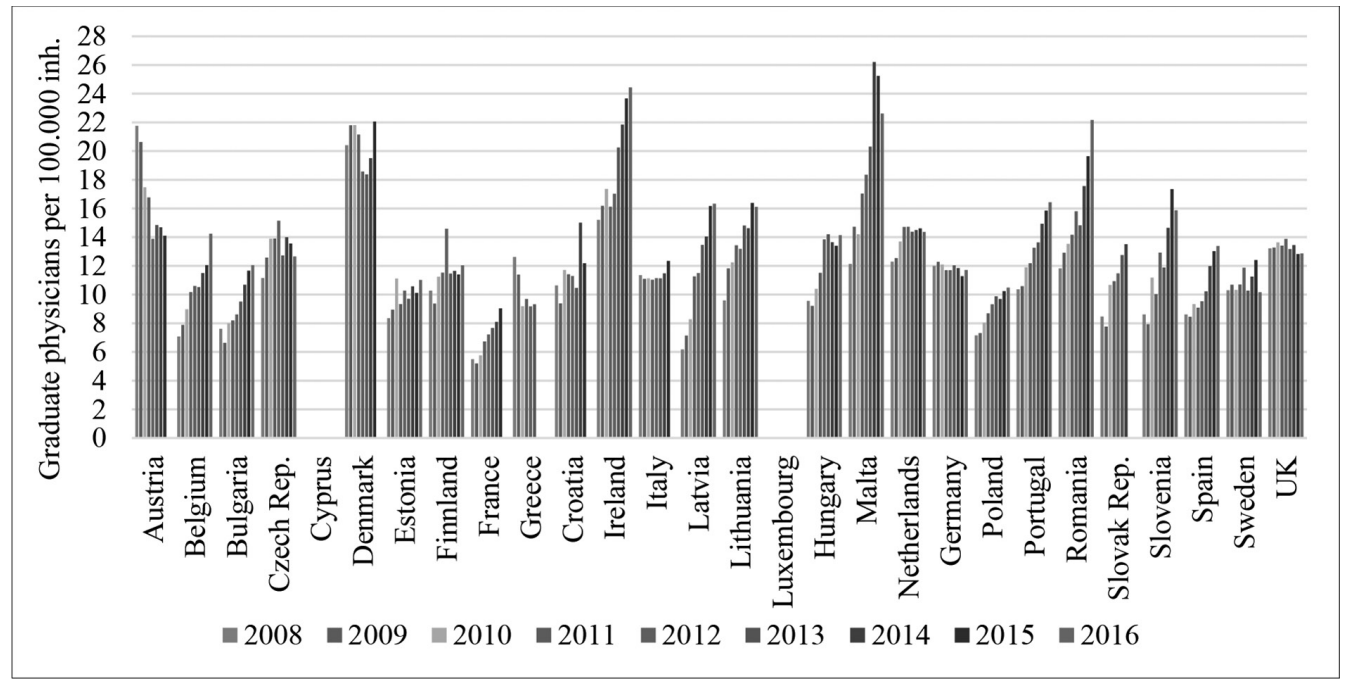

Figure 2. Number of graduate physicians per 100.000 inhabitants Source: EUROSTAT

Assuming a minimal number of 30 working years for a practising physician, a country like Romania with some 22 graduate physicians per 100.000 inhabitants could expect to have at least 600 practising physicians per 100.000 inhabitants. We find this number to be less than 300 
(Figure 3). Where did Romanian graduate medical doctors emigrate to? Some of high-income EU MSs show a growing number of physicians per 100.000 people while at the same time the number of graduate physicians in their medical schools decreased. An example is Austria where the number of physicians increased from 420 to over 500, while the number of graduate medical doctors has decreases from 21 per 100.000 inhabitants to just 14. Countries increasing the relative number of practicing physicians while decreasing the relative number of graduates need to fill the gap by immigration.

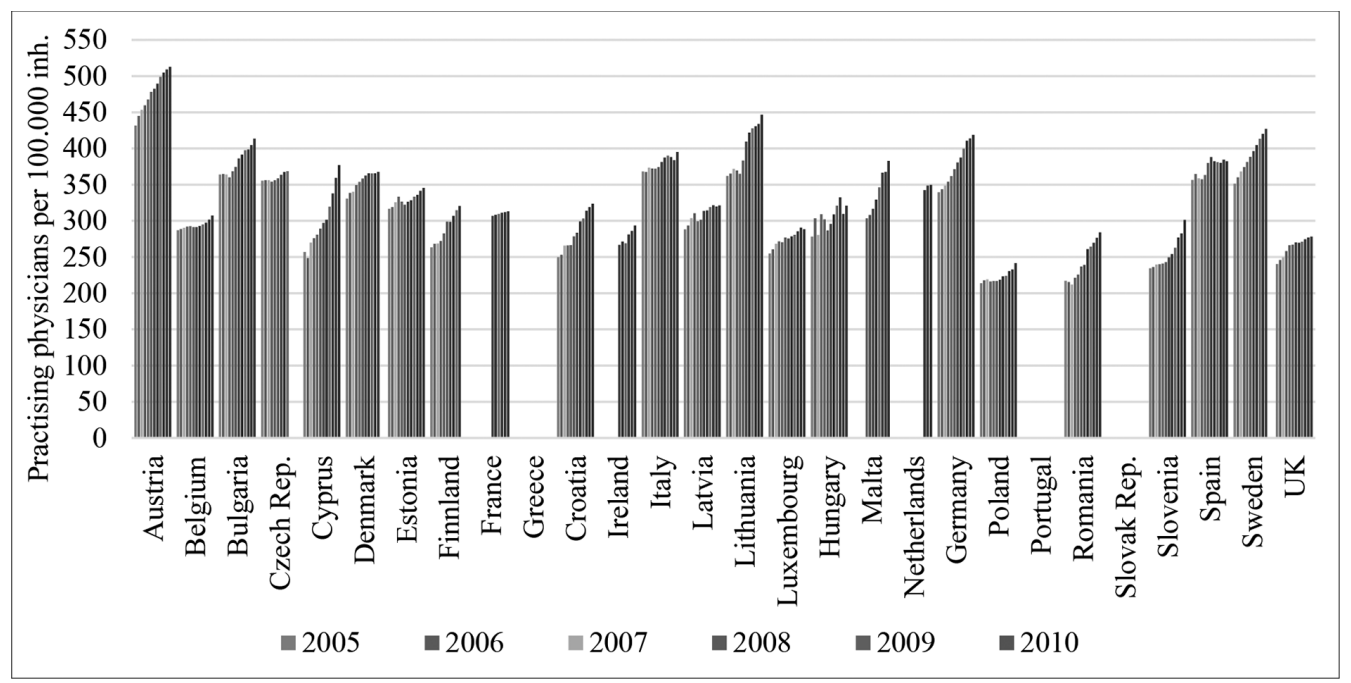

Figure 3. Number of practising physicians per 100.000 inhabitants Source: EUROSTAT

Medical studies are extremely costly in terms of time and money. By immigrating to higher income countries, while the burden of tuition fees is still socialised, the brain drain of specialised medical workforce imposes additional costs on the already poorer CEECs.

The number of employed doctors is highest in Austria, followed by Lithuania, Sweden and Bulgaria, and the lowest in Poland, the United Kingdom, Slovenia and Romania. Data for Greece, Portugal and Slovakia were not available. An upward trend can be observed in all charted countries. The upward trend is mostly due to the eldering population with simultaneous increasing incomes and growing standards of living. The resulting changes in opportunity costs require a rising share of medical care expenses within the overall distribution of the GDP.

What is peculiar when comparing the results of Figure 3 and Figure 4 is the fact that countries with the highest number of practising physicians per 100.000 inhabitants do not correspond to countries having the highest number of specialists' or generalists' consultations per inhabitant. This makes us conclude that the physicians' workload across countries is not similar. So, for example, Austria is a country with the highest number of practising physicians per 100.000 people: more than 500, and only 7 specialists' or generalists' consultations per inhabitant per year. Hungary, on the other side of the spectrum, has 11 physicians' consultations per year, and only 300 physicians per 100.000 people. Obviously, physicians' workloads are not similar across EU MSs. This might lead us to investigate the differences in quality of such diverse practices. One of the factors determining the quality of health care services besides the well qualified and experienced personnel are health care facilities and diagnostic technology. 


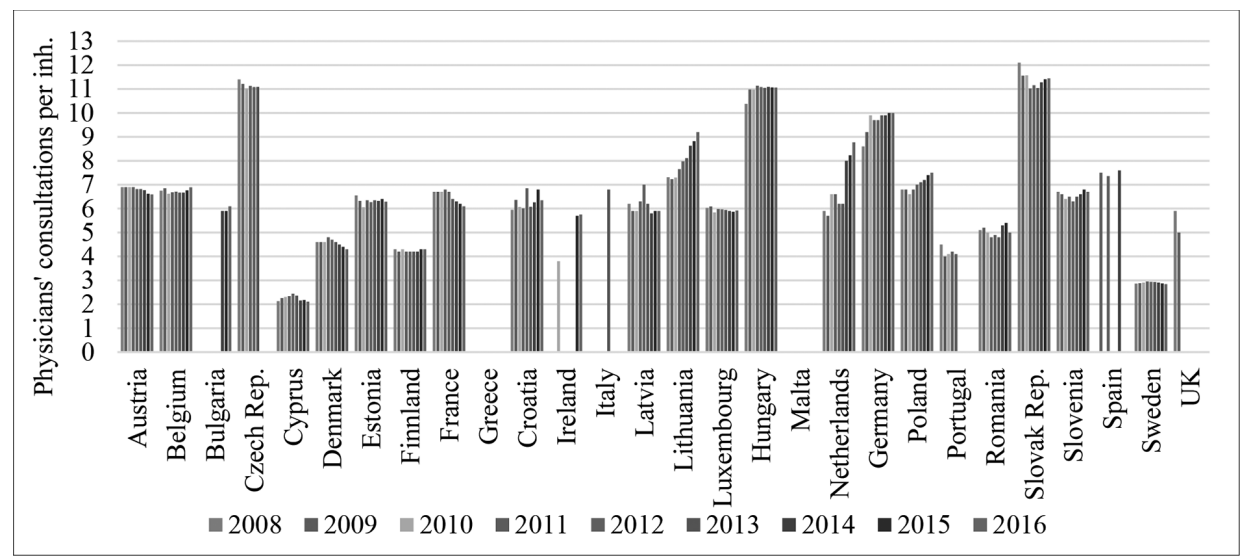

Figure 4. Number of specialists' or generalists' consultations per inhabitant Source: EUROSTAT

Health care facilities among other include hospitals, laboratories, hospices, and health centres. They are equipped with hospital beds (Figure 5), medical technology (Figures 7 and 8) and other equipment that helps to provide medical assistance to patients.

Self-reported unmet needs for diagnostics (in \%) is shown in Figure 9. As already mentioned, the country with booming unmet needs is Greece, mostly due to its financial crisis and budgetary cuts across all budgetary items. Not surprisingly, Greece does not provide us with reliable statistics on the number of medical doctors or the number of their consultations.

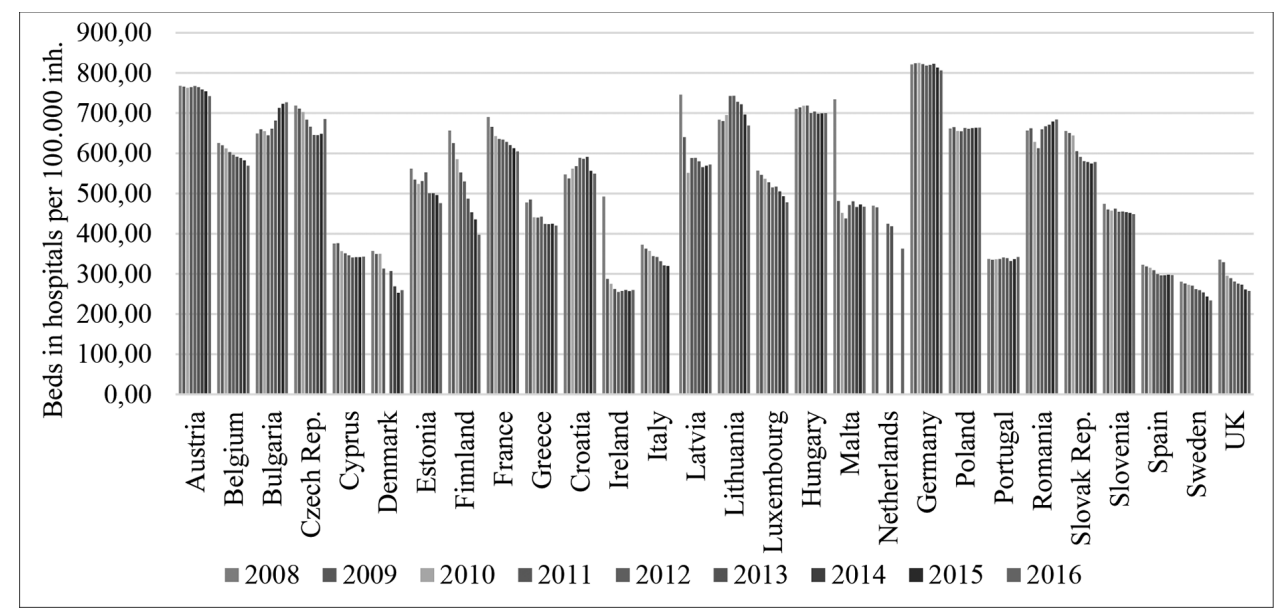

Figure 5. Number of available beds in hospitals per 100.000 inhabitants

Source: EUROSTAT

The number of hospital beds is the main indicator of hospital capacity. The number of available beds in hospitals per 100.000 inhabitants is the highest in Germany and Austria, and the lowest in Ireland, Sweden, Denmark and the United Kingdom. The number of hospital beds is showing a constant downward trend in almost every country. By reducing the number of hospital beds, attempts are made to reduce health care costs while increasing quality and efficiency. Such cost reductions could generate huge savings. Hospitals keep some beds vacant for emergencies, but too many vacancies are "sunk" costs. Hospital beds' occupancy rate shows the ability of HMOs to plan and micromanage costs at hospital level. An ideal average occupancy rate is between $80-90 \%$. It seems that countries with lower relative number of hospital beds have managed to gain a higher occupancy rate, thus increasing efficiency by decreasing "sunk" costs. 


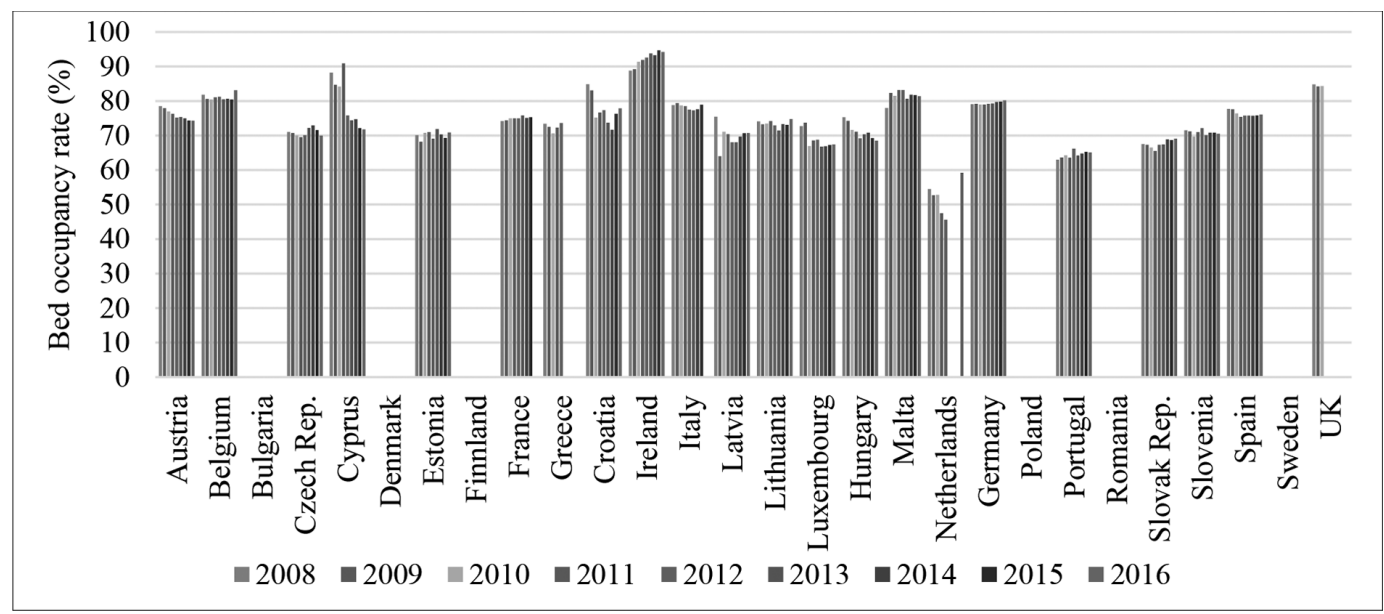

Figure 6. Curative care hospital beds' occupancy rate

Source: EUROSTAT

The highest bed occupancy rate is in Ireland (about 95\%), Cyprus (91\%) and the United Kingdom $(85 \%)$, and the lowest in Portugal (about 65\%) and the Netherlands (about $45 \%$ ). The cases of Netherlands and Portugal are examples of ,poor" utilization, with large "sunk" costs. Data for Bulgaria, Denmark, Finland, Poland, Romania and Sweden are not known.

Indicators of medical technology equipment show capital endowment of HMO's and the overall trend of a country towards new technologies. CT scanners improve diagnostics significantly in a fast and cost-effective way by reducing further needs for diagnostics and surgical procedures.

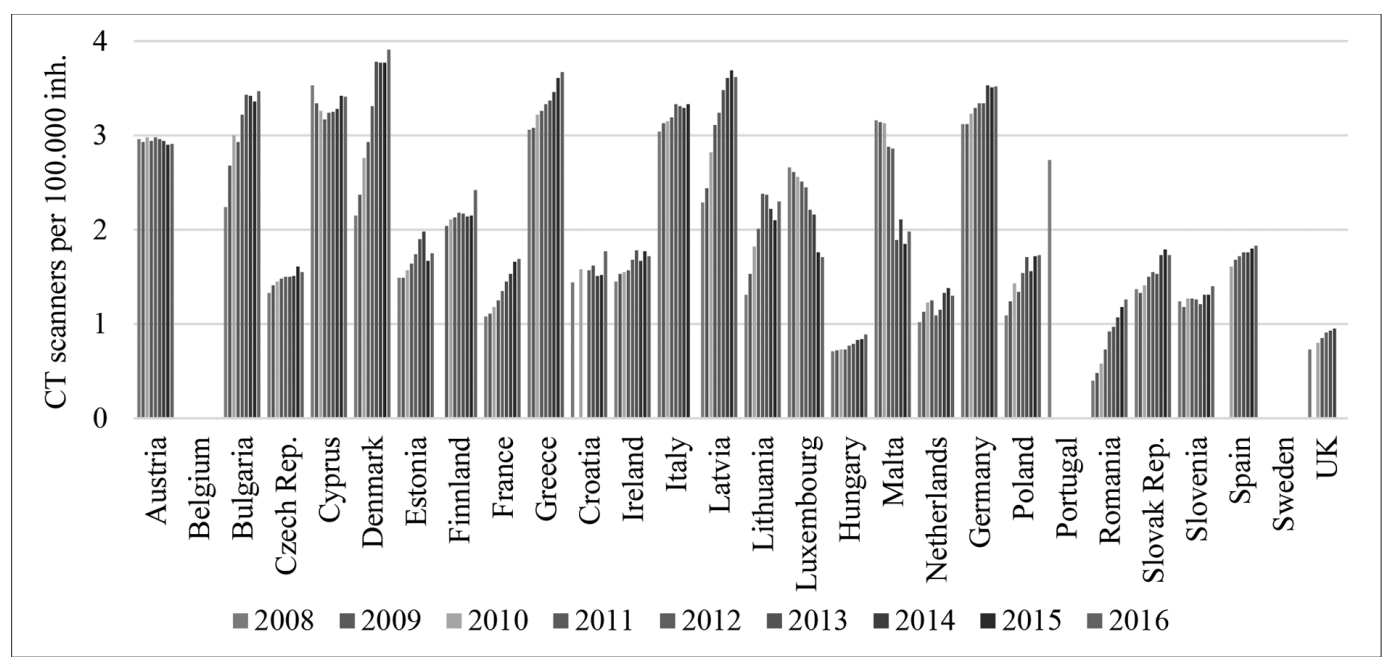

Figure 7. Number of Computed Tomography (CT) scanners per 100.000 inhabitants Data source: EUROSTAT.

The countries leading the way are: Denmark, Latvia, Germany, Greece, Cyprus, and Bulgaria, followed by Italy, Austria, and Malta. A higher number of CTs does not mean they are used optimally, so these statistics needs to be complemented by waiting list and unmet needs statistics.

Countries are rather diverse in their medical technology equipment endowments, and it seems that these endowments (or lack thereof) are not the main reason for the differences in unmet needs for diagnostics (Figure 9). 


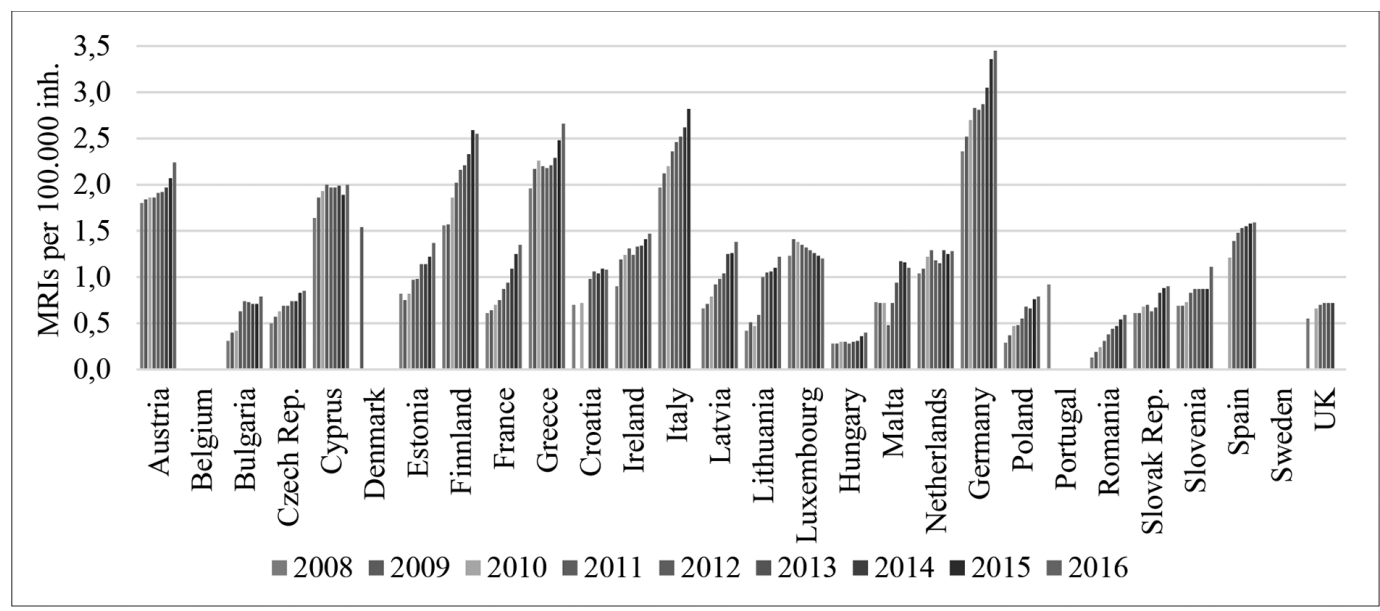

Figure 8. Magnetic Resonance Imaging (MRI) units per hundred thousand inhabitants Data source: EUROSTAT.

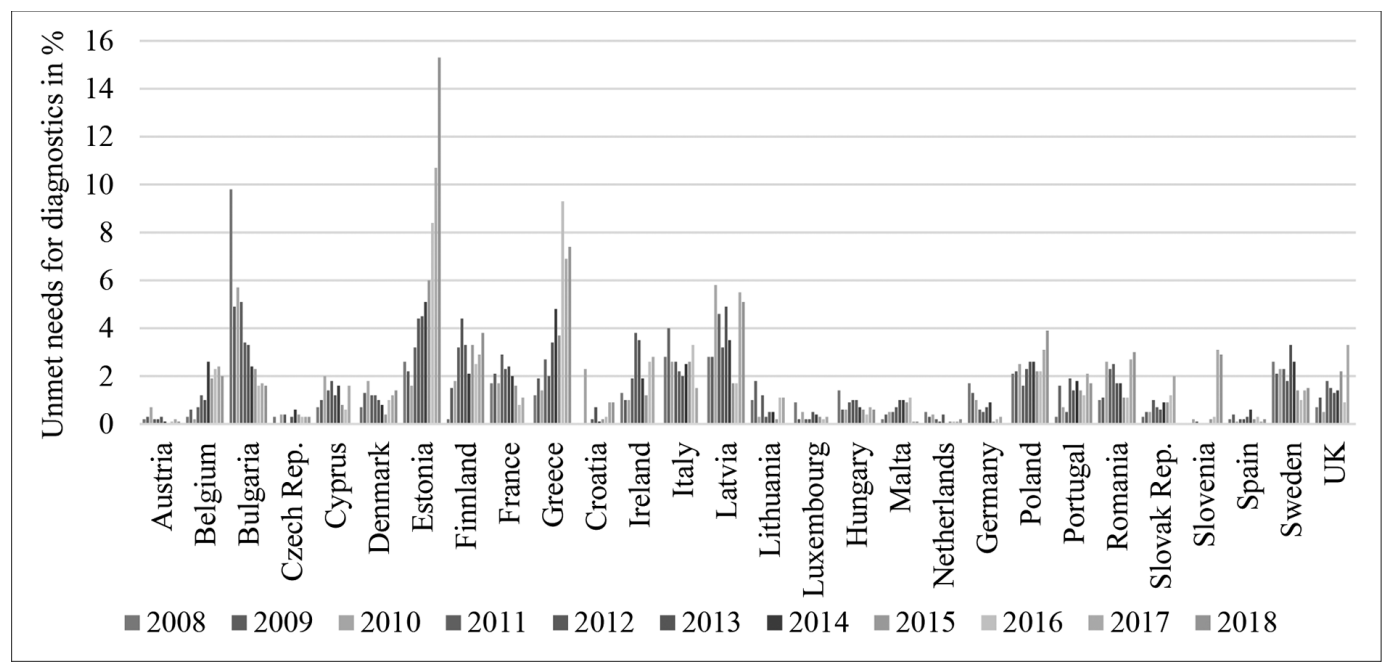

Figure 9. Self reported unmet needs for diagnostics in $\%$

Data source: EUROSTAT.

As we could not see any correlation between medical technology endowment and self-reported unmet needs for diagnostics, we conjecture a relationship with the only other factor at hand: the complementary labour factor.

\section{PROBLEMS ARISING FROM COUNTRY DIFFERENCES}

Health expenditures represent a growing share of GDP in both developed and transition countries. These expenditures in former Central and East European (CEE) transition countries typically range from $6 \%$ to $8 \%$ of GDP, while in highly developed countries, they range from $8 \%$ to $11 \%$ of the GDP. As health is a superior good, and opportunity costs of health are higher in richer countries than in poorer ones, it is expected the outlays for health care in richer countries to be higher. In 2016, France and Germany had the highest share of health expenditure per capita (private and public), and Romania and Luxembourg the lowest one. Luxembourg being the obvious outlier regarding its extremely high GDP of over $€ 100,000$ per capita. The possible reasons for Luxembourg stepping out of the line are: overrated GDP (and thus overrated denominator) over the National Income (NI) because of a heavy concentration of industries actually not contributing to the NI such as international financial services, large number of EU institu- 
tions, their employees having separate health care arrangements not being covered by domestic health care policies, and thus not being covered by the domestic statistics, and lastly, a relatively low number of performed health care interventions due to a relatively high level of health care condition of Luxembourgish citizens. Also, being a relatively small country, Luxembourg uses a lot of specialist medical services of the surrounding countries, statistically encompassed as services performed in these countries, all undervaluing the numerator.

\subsection{The impossibility of price discriminatory practices}

One of the most problematic consequences of public health system differences is the price discriminatory behaviour by the pharmaceutical industry and governmental or EU policies prohibiting such behaviour. Let us consider two examples: the first of a cure against cancer Trastuzumab (herceptin), and the second of a cure against Hepathtis $\mathrm{C}$ virus (HCV) Viekirax (a ombitasvir / paritaprevir / ritonavir combination therapy). Both therapies cost around 50.000 EUR, are very effective, and have lower priced lower effectiveness alternatives on the market (Mance et al. 2016). In low income EU MSs, people are forced to go to such lengths to get the extremely expensive medical treatment as to sell their own homes (Paun, 2016). Because of EU common market, differential prices are strictly prohibited. Any discrimination of first, second, third or even fourth degree is strictly prohibited. Nevertheless, pharma industry has come about some new non explicit methods of granting discounts to counties with a lower ability to pay.

Table 2. Four degrees of price discrimination

\begin{tabular}{|l|l|l|l|}
\hline \multicolumn{2}{|c|}{ quality } & \multicolumn{2}{c|}{ The seller targets: } \\
\cline { 3 - 4 } & \multicolumn{1}{|c|}{ quantity } \\
\hline \multirow{2}{*}{$\begin{array}{l}\text { The seller } \\
\text { targets: }\end{array}$} & individuals & $\begin{array}{l}1^{\text {st }} \text { degree price discrimination: individ- } \\
\text { ually tailored price-quality combina- } \\
\text { tions are perceived as different qualities. }\end{array}$ & $\begin{array}{l}2^{\text {nd }} \text { degree price discrimination: rebates } \\
\text { are given on incremental sales and fol- } \\
\text { low the slope of the demand curve. }\end{array}$ \\
\cline { 2 - 4 } & groups & $\begin{array}{l}4^{\text {th }} \text { degree price discrimination: } \\
\text { group-tailored price-quality differen- } \\
\text { tials. }\end{array}$ & $\begin{array}{l}3^{\text {rd }} \text { degree price discrimination: prices } \\
\text { are equal to the group mean unitary } \\
\text { elasticity of demand. }\end{array}$ \\
\hline
\end{tabular}

Source: Mance et al. (2019), p. 178.

If prohibited to price discriminate by group and quantity ( $3^{\text {rd }}$ degree of price discrimination) pharmaceutical industry may attempt to discriminate by group and quality. The danger of such discrimination schemes is that lower income countries may end up with lower quality health technologies. Prohibition of price discrimination originally meant to close the differences between countries on the EU common market. It was one of the ideas of the common market. Prohibition of price discrimination of third degree eliminates the possibility of low-income countries achieving prices commensurate to their ability to pay, and ultimately sentences them to pharmaceutical therapies of lower quality (price discrimination of fourth degree). For example, this leads to the purchase of lower quality antivirals with a lower sustained virological response. The same goes for chemotherapies, leading to a lower survival rate. Pharmaceutical therapies of lower quality ultimately lead to higher morbidity and mortality. Price discrimination is of mutual benefit to both producers and consumers in situations where the ability to pay is the major reason for not being able to purchase the pharmacological therapy. Pharmaceuticals are an industry characterised by extremely large irreversibilities in production: high fixed and sunk costs of research and development protected by patent rights. Production of pharmaceuticals is also characterised by huge cost subadditivities: economies of scale and scope, relatively small and decreasing variable and marginal costs of production. Ultimately, this leads to a natural monopoly (table 3). 
Table 3. Market classification according to irreversibilities and cost subadditivities

\begin{tabular}{|l|l|l|l|}
\hline & & \multicolumn{2}{|c|}{ Irreversibilities in production ("sunk costs") } \\
\hline & & \multicolumn{1}{c|}{ large } & \multicolumn{1}{c|}{ negligible } \\
\hline $\begin{array}{l}\text { Cost subadditivities } \\
\text { ("economies of scale) } \\
\text { scope") }\end{array}$ & large & Natural monopoly & Disciplined monopoly \\
\cline { 2 - 4 } & negligible & Market with imperfections & Normal market \\
\hline
\end{tabular}

Source: Mance et al. (2015) based on Baumol et al. 1982.

Marginal cost pricing would ultimately mean the last buyer would pay a negligible price based on marginal cost. Profit maximisation requires the supplied quantity to be set as to the point where the marginal revenue intersects with marginal costs. As pharmaceutical companies do not specifically target quantities, they will set the price to be equal to the point on the demand curve where after subtracting marginal costs its elasticity of demand is assumed to be minus unity $\left(E_{d}=-1\right)$ on every separate market. The definition of a separate market is crucial. The basic idea of an EU common market is not commensurate with separate national markets for pharmaceutical therapies. But the single payer systems of EU MSs are organised on national basis and not at EU level. Less wealthy EU MSs require their prices to reflect their lower ability to pay as unitary elasticity of demand is found at a lower price level. To hide from explicit price discounts, producers enter into implicit or hidden discount practices. Several discount mechanisms have been envisaged: pay for performance (success fee) with either no cure - no pay system or a system of paybacks. Lately, pharmaceuticals are also purchased by bundling them into complex multiple therapies so that no price of a single therapy can be identified from the bundle. Also, governmental single payer HMO's reserve the right to withhold information from price negotiations with pharmaceutical industries.

\subsection{Brain drain}

The problem of physicians' brain drain from lower income EU MSs to high income EU MSs is something that is talked about, but these claims have not yet been substantiated by viable econometrics. For example, according to Ifanti et al. (2014) the main cause generating the brain drain of Greek physicians is the financial crisis resulting in austerity measures in the public sector with the consequent public sector job insecurity, income reduction, and over-taxation, together with limited budgets for research institutes (Ifanti, 2014). According to Boncea (2014) between 2007 and 2010, 8131 medical doctors left Romania, the EU MS with some of the poorest health indicators. She confirms one more time that the gap in levels of payment is significant, but not the only cause of emigration. The main reasons behind the decision to emigrate are: poor working conditions and absent opportunities for career development and continuing education (Boncea, 2014). We constructed a Panel Ordinary Least Squares (OLS) correlation analysis of differenced data represented in Figures 2 and 3. We differenced the data to achieve strong stationarity that would permit us to conduct the OLS. Firstly, we conducted a correlation between all EU MSs (Table 4). Cyprus, Greece, Luxembourg, Netherlands, Portugal, and Slovakia were omitted because of missing comparable data.

Our first correlation shows no adverse effects between changes in practicing and graduate medical doctors. The sign of the coefficient remains positive, although the $\mathrm{R}^{2}$ is rather low, a mere 0.06 ( $p=0.0005)$. This shows that at the overall EU level, no adverse beggar-thy-neighbour "brain drain" consequences occur. To test these effects at the level of particular countries, a sample of countries was selected that show an increase in the number of practicing doctors and simultaneously a falling number of graduate medical doctors (Table 5). These countries are: Austria, Denmark, Germany, Sweden, and UK. 
Table 4. Panel OLS of FD

between practising and graduate physicians of EU MSs

Dependent Variable: D(PRACTICING)

Method: Least Squares

Sample (adjusted): 2198

\begin{tabular}{lcccr}
\hline Variable & Coefficient & Std. Error & t-Statistic & Prob. \\
\hline D(GRADUATES) & 3.027618 & 0.848260 & 3.569208 & 0.0005 \\
\hline R-squared & 0.060315 & Mean dependent var & -0.920254 \\
Adjusted R-squared & 0.060315 & S.D. dependent var & 33.45267 \\
\hline
\end{tabular}

Data source: EUROSTAT. Own calculation in Eviews 9.

Table 5. Panel OLS of FD

between practising and graduate physicians of selected EU MSs

\begin{tabular}{lcccr}
\hline $\begin{array}{l}\text { Dependent Variable: D(PRACTICING) } \\
\text { Method: Least Squares } \\
\text { Sample (adjusted): } 245\end{array}$ & & & \\
\hline Variable & Coefficient & Std. Error & t-Statistic & Prob. \\
\hline D(GRADUATES) & -8.836878 & 2.482133 & -3.560195 & 0.0009 \\
R-squared & 0.214163 & Mean dependent var & -4.120227 \\
Adjusted R-squared & 0.214163 & S.D. dependent var & 37.71665 \\
\hline
\end{tabular}

Data source: EUROSTAT. Own calculation in Eviews 9.

The panel OLS shows statistically significant $(\mathrm{p}=0.0009)$ results, with an expected negative sign and a relatively high coefficient value of -8.84 meaning that for every single graduate medical doctor less exiting the medical schools, there is an increase in the number of practising physicians equal to almost 9. If we define the „brain drain“ effect as a number of physicians missing from the domestic workforce not complemented by domestic medical schools, but by immigration instead. The effect explains $21 \%$ of the increase of the number of physicians.

\section{CONCLUSION}

We identified several problems occurring at the level of individual EU MS health management systems. Firstly, there is a problem of different opportunity costs among the MSs. Different opportunity costs require different policies, and differentiated prices.

The second problem is one of labour mobility in the health care services sector, resulting from a variety of push and pull factors leading to the brain drain of skilled professionals from poorer to richer countries, and ultimately leading to a "beggar-thy-neighbour" policies with poorer countries being on the losing end.

Each EU MS has a default system of budget allocation for specific areas based on standards of care that are ultimately dependent on available health technologies. Health expenditures represent a growing share of GDP in both developed and transition countries. These expenditures in transition countries typically range between $6 \%$ and $8 \%$ of GDP, while in high-developed countries, they range from $8 \%$ to $11 \%$. These results are commensurate with rising opportunity costs of health with rising income.

Nevertheless, because of organisational issues, some countries manage to achieve better results with less medical technology endowment. It seems that the human capital was an unaccounted factor. 


\section{REFERENCES}

Arrow, KJ (1963), Uncertainty and the welfare economics of medical care. American economic review, 53(5), 941-973. https://web.stanford.edu/ jay/health_class/Readings/Lecture01/ arrow.pdf

Baumol, W. (1982). Contestable Markets: An Uprising in the Theory of Industry Structure. American Economic Review, 72(1), 1-15. https://www.jstor.org/stable/1808571

Boncea, I. J. (2014) Brain Drain in Romania: Factors Influencing Physicians' Emigration. Journal of Community Positive Practices. Issue No. 1/XIV, pp. 064-074.

Delamaire, ML, Lafortune, G (2010), Nurses in Advanced Roles: A Description and Evaluation of Experiences in 12 Developed Countries, OECD Health Working Paper, No. 54, OECD Publishing, Paris. doi: http://dx.doi.org/10.1787/5kmbrcfms5g7-en

Devaux, M, de Looper, M (2012), Income-related Inequalities in Health Service Utilisation in 19 OECD Countries, OECD Health Working Papers, No. 58, OECD, Paris. doi: http:// dx.doi.org/10.1787/5k95xd6stnxt-en

Drummond, MF, Sculpher, MJ, Claxton, K, Stoddart, GL, Torrance, GW (2015), Methods for the Economic Evaluation of Health Care Programmes, $4^{\text {th }}$ edition, Oxford University Press, Oxford.

Ifanti, A. A.; Argyriou, A. A.; Kalofonou, F. H.; Kalofonos, H. P. (2014) Physicians' brain drain in Greece:Aperspectiveonthereasons whyandhowtoaddressit.HealthPolicy,117(2),pp.210-215. doi: https://doi.org/10.1016/j.healthpol.2014.03.014

Mance D, Vretenar N, Katunar J (2015) Opportunity cost classification of goods and markets. International Public Administration Review, Vol. 13(1):119-134. doi: 10.17573/ipar.2015.1.06

Mance D, Mance D, Vitezić D (2016) Incremental cost-effectiveness pharmacoeconomic assessment of hepatitis $C$ virus therapy: an approach for less wealthy members of the common market. Croat Med J 57(6):582-590.

Mance D., Mance D., Vitezić D. (2019) Personalized Medicine and Personalized Pricing: Degrees of Price Discrimination. In: Bodiroga-Vukobrat N., Rukavina D., Pavelić K., Sander G. (eds) Personalized Medicine in Healthcare Systems. Europeanization and Globalization, vol 5. Springer, Cham. doi: https://doi.org/10.1007/978-3-030-16465-2_14.

Ottewill, R (1996), Health Care Systems in Liberal Democracies, London and New York: Routledge.

Paun, C. (2016) Skyhigh drug prices made Romania mull unusual path. Politico, Europe edition. https://www.politico.eu/article/high-drug-prices-romania-changes-patents-hepatitis/

Santerre, RE, Neun, SP (2007), Health economics, theories, insights, and industry studies, $4^{\text {th }}$ edition, Steve Momper, Thomson, South-Western. 